\title{
Reciprocal regulation of integrin $\beta 4$ and KLF4 promotes gliomagenesis through maintaining cancer stem cell traits
}

\author{
Binbin $\mathrm{Ma}^{1+}$, Li Zhang ${ }^{2+}$, Yujie Zou ${ }^{3+}$, Ruiping He' , Qiong Wu${ }^{4}$, Chuanchun Han ${ }^{1 *}$ and Bo Zhang ${ }^{1 *}$
}

\begin{abstract}
Background: The dismal prognosis of patients with glioma is largely attributed to cancer stem cells that display pivotal roles in tumour initiation, progression, metastasis, resistance to therapy, and relapse. Therefore, understanding how these populations of cells maintain their stem-like properties is critical in developing effective glioma therapeutics.

Methods: RNA sequencing analysis was used to identify genes potentially involved in regulating glioma stem cells (GSCs). Integrin $\beta 4$ (ITGB4) expression was validated by quantitative real-time PCR (qRT-PCR) and immunohistochemical (IHC) staining. The role of ITGB4 was investigated by flow cytometry, mammosphere formation, transwell, colony formation, and in vivo tumorigenesis assays. The reciprocal regulation between Integrin $\beta 4$ and KLF4 was investigated by chromatin immunoprecipitation (ChIP), dual-luciferase reporter assay, immunoprecipitation, and in vivo ubiquitylation assays.
\end{abstract}

Results: In this study, we found that ITGB4 expression was increased in GSCs and human glioma tissues. Upregulation of ITGB4 was correlated with glioma grades. Inhibition of ITGB4 in glioma cells decreased the self-renewal abilities of GSCs and suppressed the malignant behaviours of glioma cells in vitro and in vivo. Further mechanistic studies revealed that KLF4, an important transcription factor, directly binds to the promoter of ITGB4, facilitating its transcription and contributing to increased ITGB4 expression in glioma. Interestingly, this increased expression enabled ITGB4 to bind KLF4, thus attenuating its interaction with its E3 ligase, the von Hippel-Lindau (VHL) protein, which subsequently decreases KLF4 ubiquitination and leads to its accumulation.

Conclusions: Collectively, our data indicate the existence of a positive feedback loop between KLF4 and ITGB4 that promotes GSC self-renewal and gliomagenesis, suggesting that ITGB4 may be a valuable therapeutic target for glioma.

Keywords: Glioma stem cells, ITGB4, KLF4, Tumourigenesis

\section{Background}

Glioma is the most common primary malignant brain tumour of the central nervous system. Despite great advances in therapeutic techniques for treating glioma, such as surgery, radiotherapy, and chemotherapy, patients with glioblastoma (GBM) still only have an average survival of 12-15 months [1-4]. Accumulating evidence suggests that glioma are functionally heterogeneous and harbour a subset of tumour cells with stem cell characteristics, including the preferential expression of stem cell markers,

\footnotetext{
*Correspondence: hanchuanchun@163.com; zhangbodl@126.com ${ }^{\dagger}$ Binbin Ma, Li Zhang and Yujie Zou contributed equally to this work. ${ }^{1}$ Department of Neurosurgery, Second Affiliated Hospital, Institute of Cancer Stem Cell, Dalian Medical University, Dalian 116027, China Full list of author information is available at the end of the article
}

enhanced self-renewal ability, and multi-lineage differentiation potential. Those cells are termed glioma stem cells (GSCs) and are highly capable of initiating tumour growth or repopulating tumours after treatment [5-8].

Recently, studies have increasingly demonstrated that GSCs are highly adaptive to various crucial conditions such as nutrient-restricted conditions, hypoxia, or chemoagent exposure, and actively interact with microenvironmental factors to evade antitumour immune responses, promoting tumour angiogenesis and tumour invasion. Because of these characteristics, GSCs are considered to be responsible for tumour recurrence and the poor outcomes of glioma patients [9-11]. Therefore, investigation of the key regulators involved in maintaining these GSC 
traits is of great importance to understand glioma progression and to develop novel treatment approaches.

Integrin $\beta 4$ (ITGB4) also known as CD104 is a laminin-5 receptor which is predominantly expressed in squamous epithelial cells, endothelial cells, immature thymocytes, Schwann cells, and fibroblasts of the peripheral nervous system [12]. In tumours, ITGB4 was first discovered as a tumour-specific antigen. Subsequent studies demonstrated that increased expression levels of ITGB4 were correlated with malignant progression and poor survival rates in squamous cell carcinomas (SCCs) of the skin, lung, head and neck, and cervix [13-15]. Further studies have reported that high expression levels of ITGB4 were found in several types of cancer-including breast, bladder, colon, ovarian, pancreatic, prostate, and thyroid-and were linked to poor prognosis [16-18]. In tumour tissues, the phosphorylation of the cytoplasmic tail of ITGB4 leads to its release from hemidesmosomes and its interaction with growth factor receptors, which promotes the invasion and metastasis of tumour cells [18]. Although ITGB4 has been reported to promote tumourigenesis in many cancers, its role in glioma is still unknown.

Here, we show for the first time that ITGB4 expression is increased in GSC and glioblastoma tissues. Elevated levels of ITGB4 maintained the stem-like properties of GSCs, promoted glioma cell migration and tumorigenesis, and were associated with glioma grades. Further mechanistic studies revealed that KLF4, an important transcription factor, could directly bind to the promoter of ITGB4, facilitating its transcription and contributing to increased ITGB4 expression in glioma. Simultaneously, we found that ITGB4 interacted with KLF4 and decreased its binding to the E3 ligase VHL in glioma cells, which subsequently enhanced KLF4 stability and increased KLF4 expression. Thus, our study reveals that a novel feedback loop exists between KLF4 and ITGB4, which contributes to GSC self-renewal and glioma tumourigenesis.

\section{Methods}

\section{Cell cultures and reagents}

Human glioma cell lines LN229 and U251 were obtained from the American Type Culture Collection (ATCC). LN229 and U251 cells were cultured with DMEM supplemented with $10 \%$ foetal bovine serum FBS (ExCell Bio, Lot: FSP500), $2 \mathrm{mM}$ L-glutamine, penicillin $(100 \mathrm{U} / \mathrm{mL})$, streptomycin $(100 \mu \mathrm{g} / \mathrm{mL})$ and $0.1 \%$ Savelt ${ }^{\mathrm{tax}}$ (Hanbio Co. Ltd., 1:1000) in a humidified atmosphere of $5 \% \mathrm{CO}_{2}$ maintained at $37^{\circ} \mathrm{C}$. The medium was replaced every day, and the cells were passaged before reaching confluence. The following antibodies were used in this study: Nanog (Cell Signaling Technology; \#3580), OCT4 (Cell Signaling
Technology; \#2750), KLF4 (Santa Cruz Biotechnology, SC-20691), KLF4 (Cell Signaling Technology, \#12173S), ITGB4 (Proteintech, 21738-1-AP), ITGB4 (Abcam, ab29042), VHL (Cell Signaling; \#68547), Beta-actin (Proteintech, 6609-1-lg).

\section{Flow cytometry}

Antibodies for CD133 were purchased from Miltenyi Biotec. Briefly, $10 \mu \mathrm{L}$ of the antibodies were used to mark $10^{6}$ cells per $100 \mu \mathrm{L}$ of buffer for $30 \mathrm{~min}$, in the dark, in a refrigerator $\left(2^{\circ} \mathrm{C}-8^{\circ} \mathrm{C}\right)$, and the marker cells were analysed (BD Accuri C6). For the ALDH1 assay, the ALDH1+ population was detected with an ALDEFLUOR kit (Shanghai Stem Cell Technology Co. Ltd., Shanghai, China) following the manufacturer's instructions. The ALDH1+ and ITGB4 + cells were analysed by flow cytometry (BD Accuri C6) or sorted (BD FACSCanto II).

\section{Mammosphere formation assay}

Spheres were enriched from LN229 and U251 cells by culturing 200 to 1000 cells $/ \mathrm{mL}$ in serum-free DMEM-F12 medium (Gibco) supplemented with B27 (1:50, Invitrogen) and $20 \mathrm{ng} / \mathrm{mL}$ EGF and bFGF. Nontreated tissue culture flasks were used to reduce cell adherence and support growth as undifferentiated tumour spheres. Cells were cultured for 2 weeks, and the number of spheres with a diameter of more than $100 \mathrm{~mm}$ in each well was counted.

\section{Lentiviral transfection and RNA interference}

The lentiviral particles for transduction of shRNA-mediated knockdown of ITGB4 and KLF4 were expressed using pLKO.1 vector. The shRNA sequences used for targeting are as follows: ITGB4, 5'-GAGGGTGTCATCACCATTG AA-3' (\#2) and 5' ${ }^{\prime}$-CCAGCGACTACACTATTGGAT-3' (\#1) and KLF4, 5'-ATCGGTCATCAGCGTCAGCAA-3' (\#1); 5'-AAGTCATCTTGTGAGTGGATAA-3' (\#2).

\section{Real-time RT-PCR and RT-PCR}

Total RNA was isolated using TRIzol (Invitrogen). One microgram of total RNA was used to synthesize cDNA using a PrimeScript ${ }^{\mathrm{Tm}}$ RT reagent kit (Takara, RR047A) according to the manufacturer's instructions. The sequences of the primers used are as follows: Actin F: 5'-GACCTGACTGACTACCTCATGAAGAT-3' and R: 5'-GTCACACTTCATGATGGAGTTGAAGG-3'; OCT 4 F: 5' - AGAACATGTGTAAGCTGCGG-3' and R: 5'-GTTGCCTCTCACTCGGTTC-3'; Nanog F: 5'-GA AATACCTCAGCCTCCAGC-3' and R: 5'-GCGTCACA CCATTGCTATTC-3'; KLF4 F: 5' -ACCTACACAAAGA GTTCCCATC-3', R: 5'-TGTGTTTACGGTAGTGCCT G-3'. 
Dual-luciferase reporter assay

The assay was performed as previously described [19].

\section{ChIP assay}

The ChIP assay was performed as previously described [20].

Immunoprecipitation and in vivo KLF4 ubiquitylation assay Cells were transfected with the indicated plasmids using Lipofectamine 3000 (Invitrogen) reagent according to the manufacturer's protocol. For immunoprecipitation assays, cells were lysed with NP40 lysis buffer (50 mM Tris- $\mathrm{HCl}, \mathrm{pH} 8.0,150 \mathrm{mM} \mathrm{NaCl}, 1 \% \mathrm{NP} 40,0.5 \%$ deoxycholate) supplemented with protease-inhibitor cocktail (Biotool). Immunoprecipitations were performed using the KLF4 antibody and protein A/G agarose beads (Santa Cruz) at $4{ }^{\circ} \mathrm{C}$. The immunocomplexes were then washed twice with $200 \mu \mathrm{L}$ PBS. Both lysates and immunoprecipitates were examined using the indicated primary antibodies followed by detection with the corresponding secondary antibodies and Western Bright ECL chemiluminescent detection reagent (Advansta).

For in vivo deubiquitylation assays, HA-ubiquitin was transfected into LN229 cells, with or without ITGB4 knockdown, or overexpressed using Lipofectamine 3000. Twenty-four hours later, the cells were treated with $20 \mu \mathrm{M}$ of the proteasome inhibitor MG132 (Calbiochem) for $8 \mathrm{~h}$. Then, cells were lysed with NP40 lysis buffer and incubated with anti-KLF4 antibody for $3 \mathrm{~h}$ and protein $\mathrm{A} / \mathrm{G}$ agarose beads (Santa Cruz) for a further $6 \mathrm{~h}$ at $4{ }^{\circ} \mathrm{C}$. The beads were then washed three times with PBS buffer. The proteins were released from the beads by boiling in SDS-PAGE sample buffer and analysed by immunoblotting with anti-Ub monoclonal antibody.

\section{Protein half-life assay}

For the KLF4 half-life assay, the LN229 cells with or without stably expressing ITGB4 or the indicated shRNAs, were treated with CHX (Sigma, $10 \mathrm{mg} / \mathrm{mL}$ ) for the indicated durations before collection. The cell lysates were examined using the indicated primary antibodies followed by detection with the related secondary antibodies and Western Bright ECL chemiluminescent detection reagent (Advansta).

\section{Colony formation assay}

LN229 and U251, with or without ITGB4 knockdown, were harvested and mixed by pipetting to become single-cell suspensions in complete culture media of a given concentration. Dilutions were made of the single-cell suspensions to 500 or 1000 cells in every well of 6-well plate. This was incubated at $37^{\circ} \mathrm{C}$ with $5 \% \mathrm{CO}_{2}$ for 2 weeks. The colonies were then stained with $0.04 \%$ crystal violet-2\% ethanol in PBS. Photographs of the stained colonies were then taken.

\section{Cell migration assay}

Cell migration assays were performed in 24-well transwell plates with $8-\mathrm{mm}$ polyethylene terephalate membrane filters (Corning) separating the lower and upper culture chambers. In brief, LN229 or U251 cells were plated in the upper chamber at $1 \times 10^{4}$ cells per well in serum-free DMEM medium. The bottom chamber contained DMEM medium with $10 \%$ FBS. Cells were allowed to migrate for $24 \mathrm{~h}$ in a humidified chamber at $37{ }^{\circ} \mathrm{C}$ with $5 \% \mathrm{CO}_{2}$. After the incubation period, the filter was removed and non-migrant cells on the upper side of the filter were detached using a cotton swab. Filters were fixed with $4 \%$ formaldehyde for $15 \mathrm{~min}$ and cells located in the lower filter were stained with $0.1 \%$ crystal violet for $20 \mathrm{~min}$ and photographed.

\section{Tumour growth assay}

Animal studies were conducted in accordance with the National Institute of Health Guide for the Care and Use of Laboratory Animals with the approval of the Animal Research Committee of Dalian Medical University. Male nude mice (4-6 weeks of age, 18$20 \mathrm{~g}$ ) were obtained from the SPF Laboratory Animal Center of Dalian Medical University (Dalian, China) and were randomly divided into the indicated groups. The mice in each group $(n=6)$ were subcutaneously injected with the indicated cells. After 15 days, tumour size was measured every 5 days by Vernier callipers and converted to TV according to the following formula: TV $\left(\mathrm{mm}^{3}\right)=\left(\mathrm{axb}^{2}\right) / 2$, where a and $\mathrm{b}$ are the largest and smallest diameters, respectively. All animals were killed 5 weeks after injection, and the transplanted tumours were removed, weighed, and fixed for further study.

\section{Tissue microarrays and immunohistochemistry}

Glioma tissue microarrays were purchased from Alenabio and Shanghai Outdo Biotech Company. These contained a total of 112 glioma tissues and 8 normal tissues. Immunohistochemistry was performed as previously described [21]. The characteristics of the patients and their tumours were collected through the review of medical records and pathology reports. Informed consent with approval of the ethics committee of Taizhou Hospital of Zhejiang Province was obtained. All of the methods in this study were in accordance with the approved guidelines, and all of the experimental protocols were approved by the ethics committee of Taizhou Hospital of Zhejiang Province. 
For immunohistochemistry, sections were subjected to antigen retrieval using microwave heating at $95^{\circ} \mathrm{C}$ in citrate buffer $(\mathrm{pH}=6.0)$. The indicated antibodies specific for KLF4 and ITGB4 were diluted according to the manufacturer's instructions. The degrees of immunostaining were reviewed and scored by two independent observers. The proportion of the stained cells and the extent of the staining were used as the criteria for evaluation. For each case, at least 1000 tumour cells were analysed. For each sample, the proportion of KLF4 and ITGB4 expressing cells varied from 0 to $100 \%$, and the intensity of staining varied from weak to strong. One score was given according to the percentage of positive cells as: $<5 \%$ of the cells: 1 point; $6-35 \%$ of the cells: 2 points; $36-70 \%$ of the cells: 3 points; $>70 \%$ of the cells: 4 points. Another score was given according to the intensity of staining as: negative staining: 1 point; weak staining (light yellow): 2 points; moderate staining (yellowish brown): 3 points; and strong

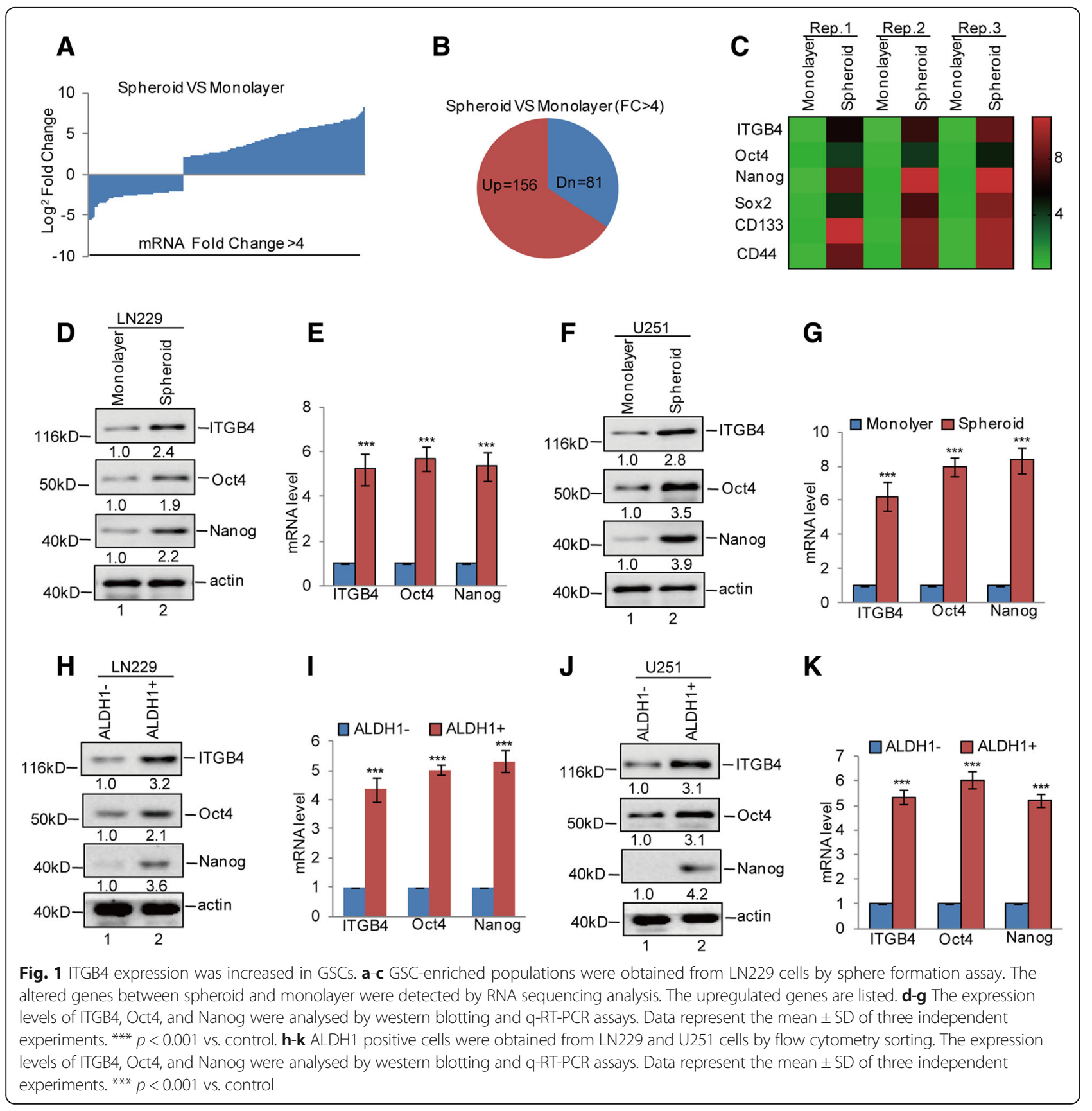


staining (brown): 4 points. A final score was then calculated by multiplying the above two scores. If the final score was equal to or larger than four, the protein expression in the tumour was considered high; otherwise, the protein expression in the tumour was considered low.

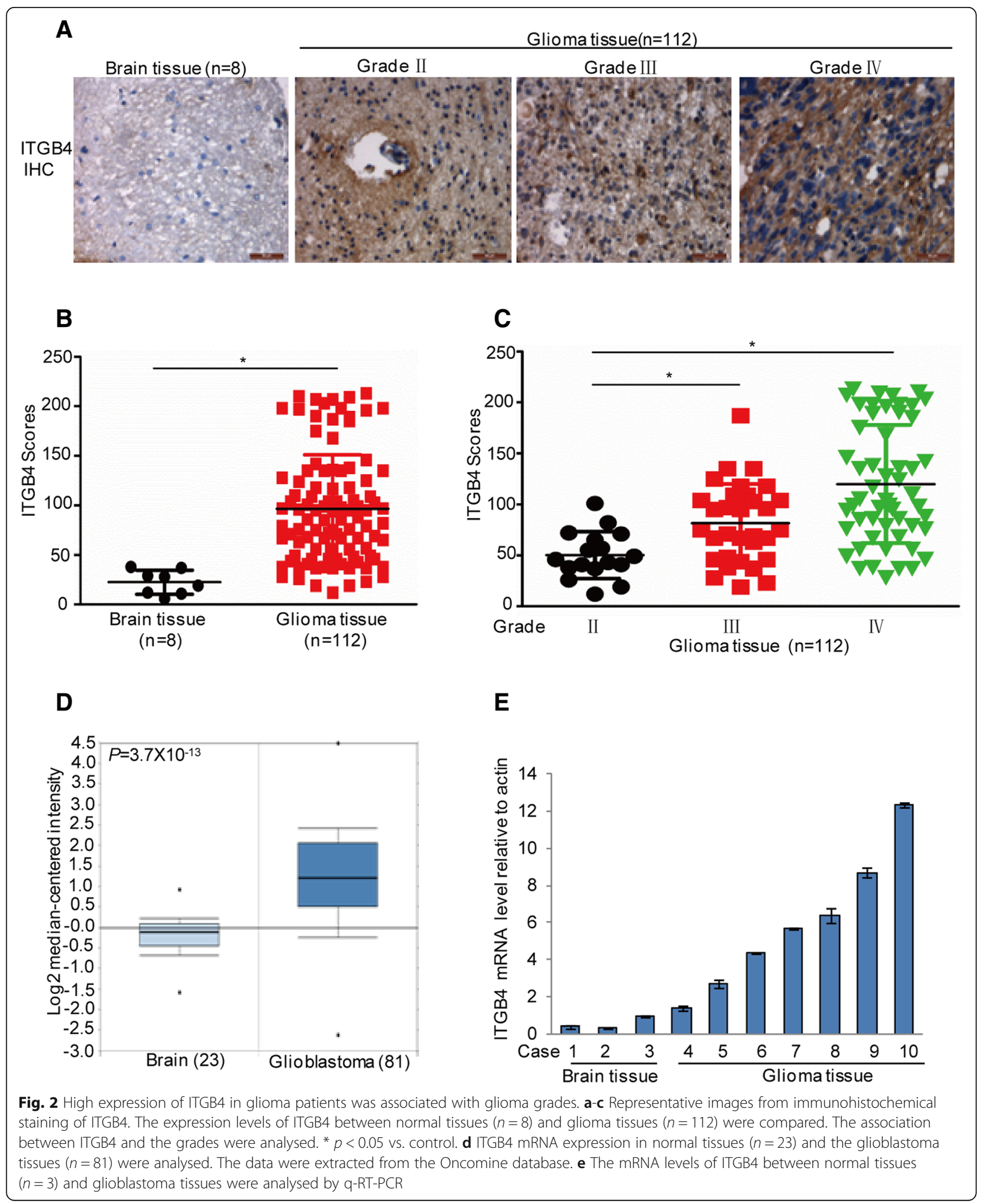




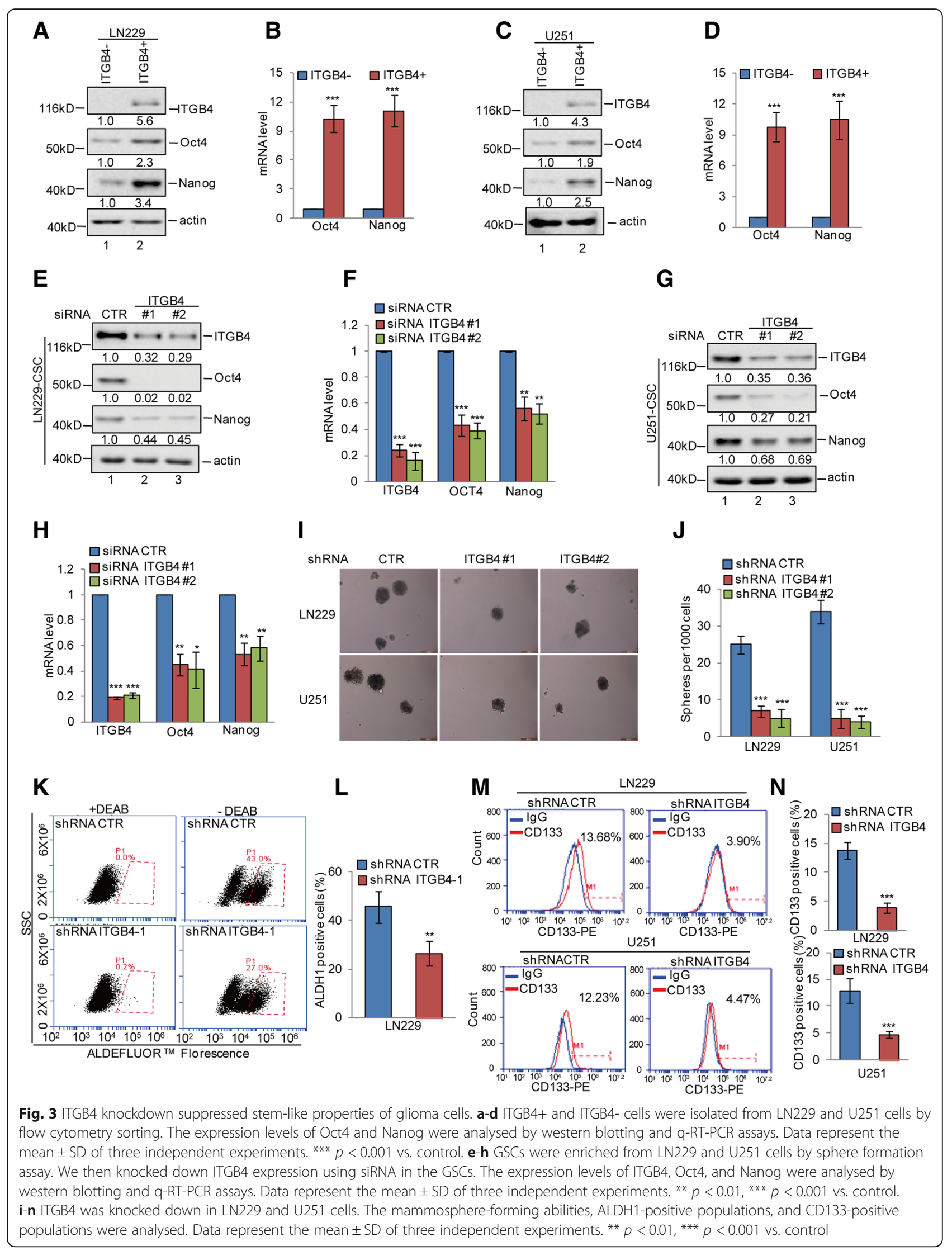


We compared ITGB4 mRNA expression in normal tissues and in glioma tissue by searching the gene symbol "ITGB4 and fold change $>1.5$ " in the Oncomine database. The data of 81 glioma tissues and 23 normal brain tissues were obtain from Sun brain
(180) 204989_s_at; diffuse astrocytoma tissues $(n=7$, Sun brain (180), 214292_at), anaplastic astrocytoma tissues $(n=19$, Sun brain (180), 211905_s_at), and classic medulloblastoma $(n=46$, Pomeroy brain (85) X53587_at).

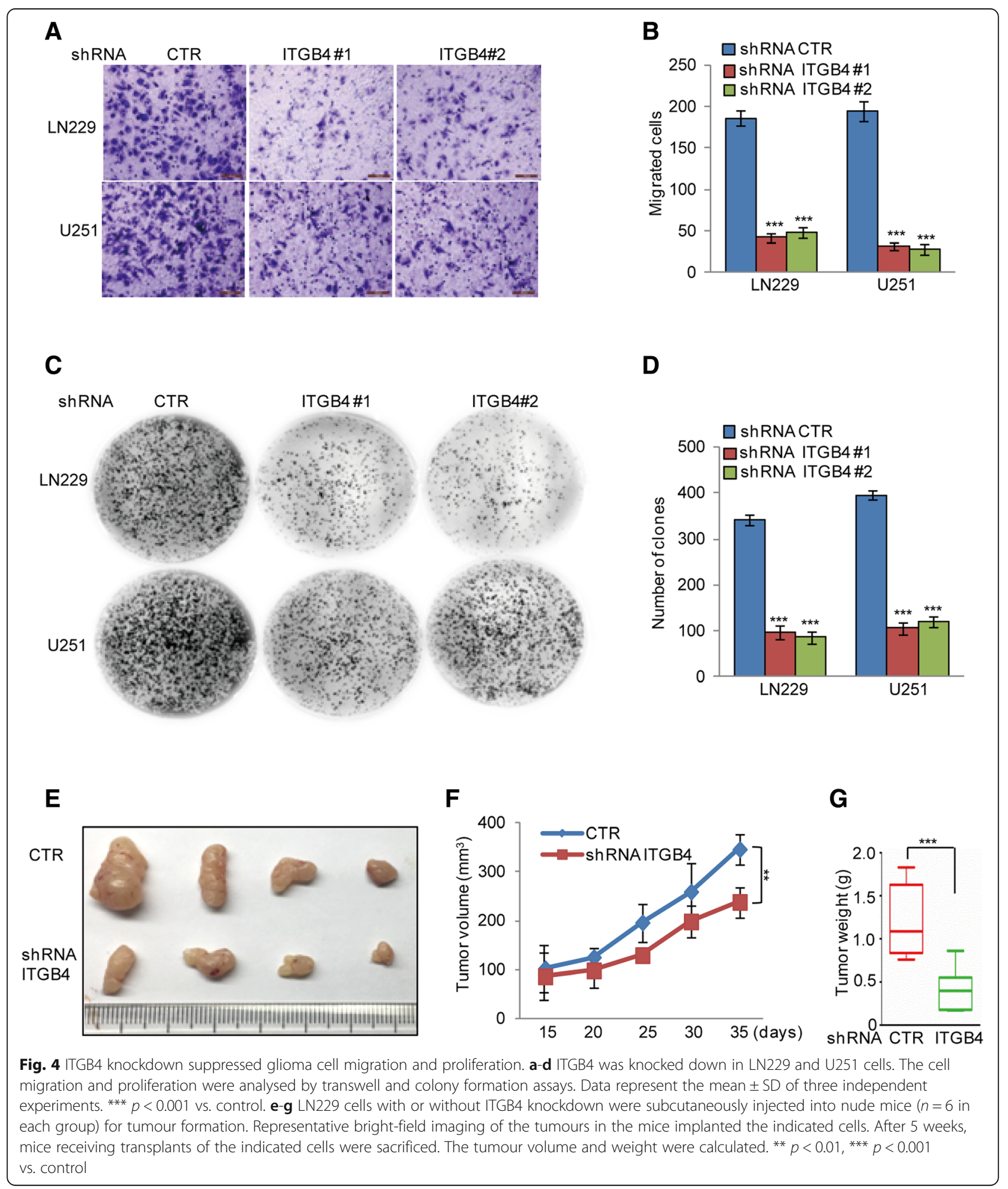




\section{Statistics and data analyses}

Statistical evaluations were performed using GraphPad Prism 5. Data are shown as mean \pm SD. Multiple comparisons between treatment groups and controls were performed using Dunnett's least significant difference (LSD) test. Statistical significance between groups was calculated using the LSD test in SPSS 17.0 software (IBM). The results of WB were analyzed using the Image $\mathrm{J}$ software. Values of $p<0.05$ were considered statistically significant.

\section{Results}

ITGB4 expression is elevated in GSC-enriched populations To identify the genes that are expressed differentially in GSCs, we first conducted a mammosphere formation assay to enrich GSCs from the glioma cell LN229 line, for subsequent mRNA sequencing analysis. Compared with the cells grown in monolayer cultures, we found 156 upregulated genes and 81 downregulated genes in GSCs (Fig. 1a and b). Among these genes, we found that ITGB4 expression was significantly increased in GSCs, which was confirmed by subsequent western blotting and q-RT-PCR assays. The upregulation of GSC markers Oct4, Nanog, Sox2, CD133, and CD44 were listed as the positive control (Fig. 1c-g). To further confirm this, we next enriched glioma stem cells from LN229 and U251 cells by ALDH1positive sorting assay and found that ALDH1+ cells also exhibited much higher ITGB4 mRNA and

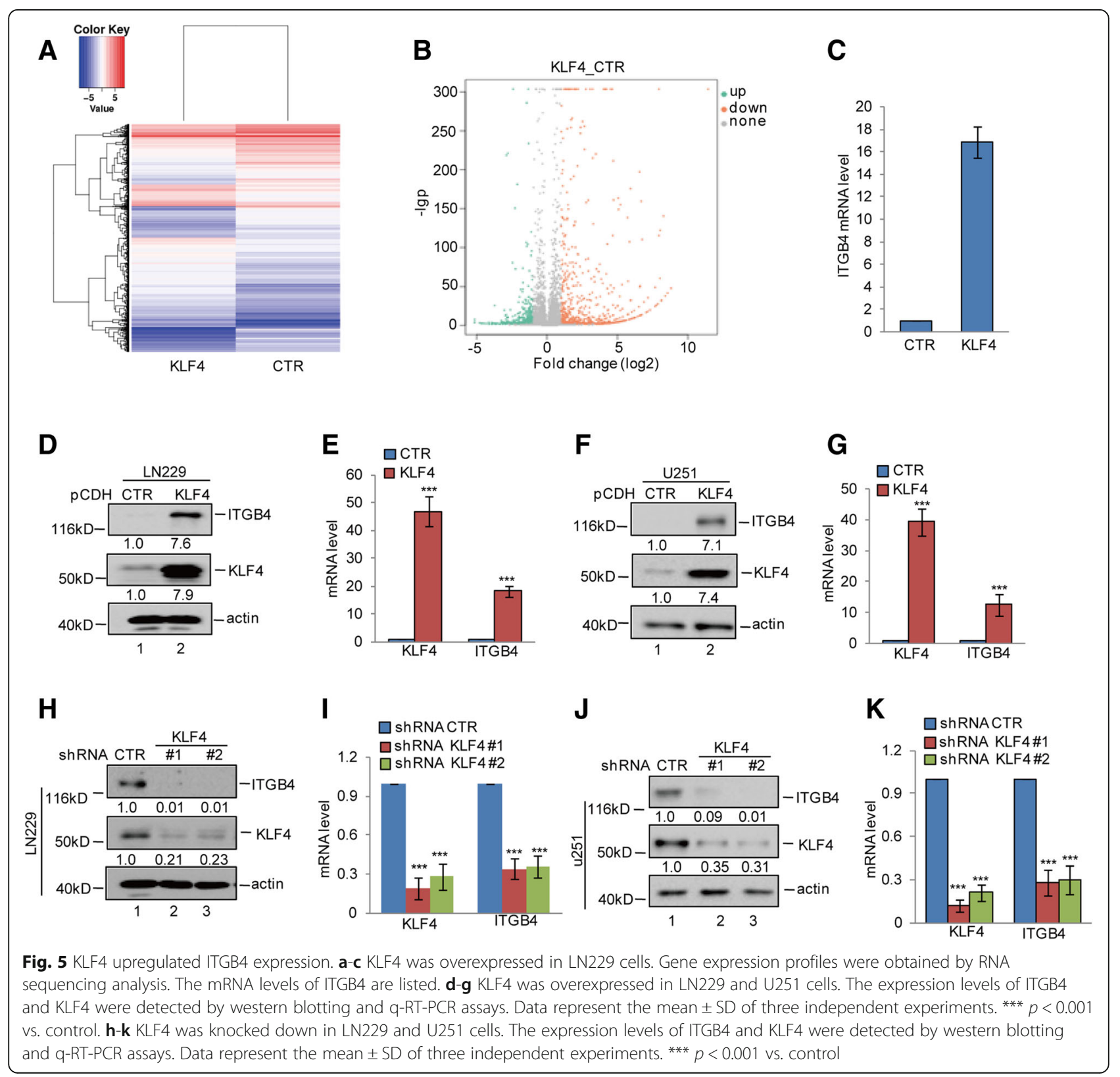


protein expression levels than ALDH1- cells (Fig. 1h-k). Together, these data suggest that ITGB4 expression is elevated in GSC-enriched populations.

ITGB4 is highly expressed in human glioma tissues and is positive correlated with glioma grades

To better understand the role of ITGB4 in the development of human glioma, we further examined ITGB4 expression in human glioma samples $(n=112$; World Health Organization (WHO) grade II-IV) and nonneoplastic brain tissue samples $(n=8)$ by immunohistochemical (IHC) staining. The IHC staining indicated that ITGB4 expression levels were increased in human glioma samples relative to normal brain tissues (Fig. 2a-b). Interestingly, increased ITGB4 levels were found in high-grade gliomas and high ITGB4 expression was significantly correlated with increased tumour grade (Fig. 2c). Subsequently, the mRNA levels of ITGB4 were assessed in 81 glioma tissues and 23 normal brain tissues, using gene expression data obtained from the Oncomine database. Correspondingly, compared with normal brain tissues, ITGB4 mRNA levels were upregulated in glioblastoma tissues (Fig. 2d). Similar results were obtained in diffuse astrocytoma tissues $(n=7)$, anaplastic astrocytoma tissues $(n=19)$, and classic medulloblastoma $(n=46)$ (Additional file 1:

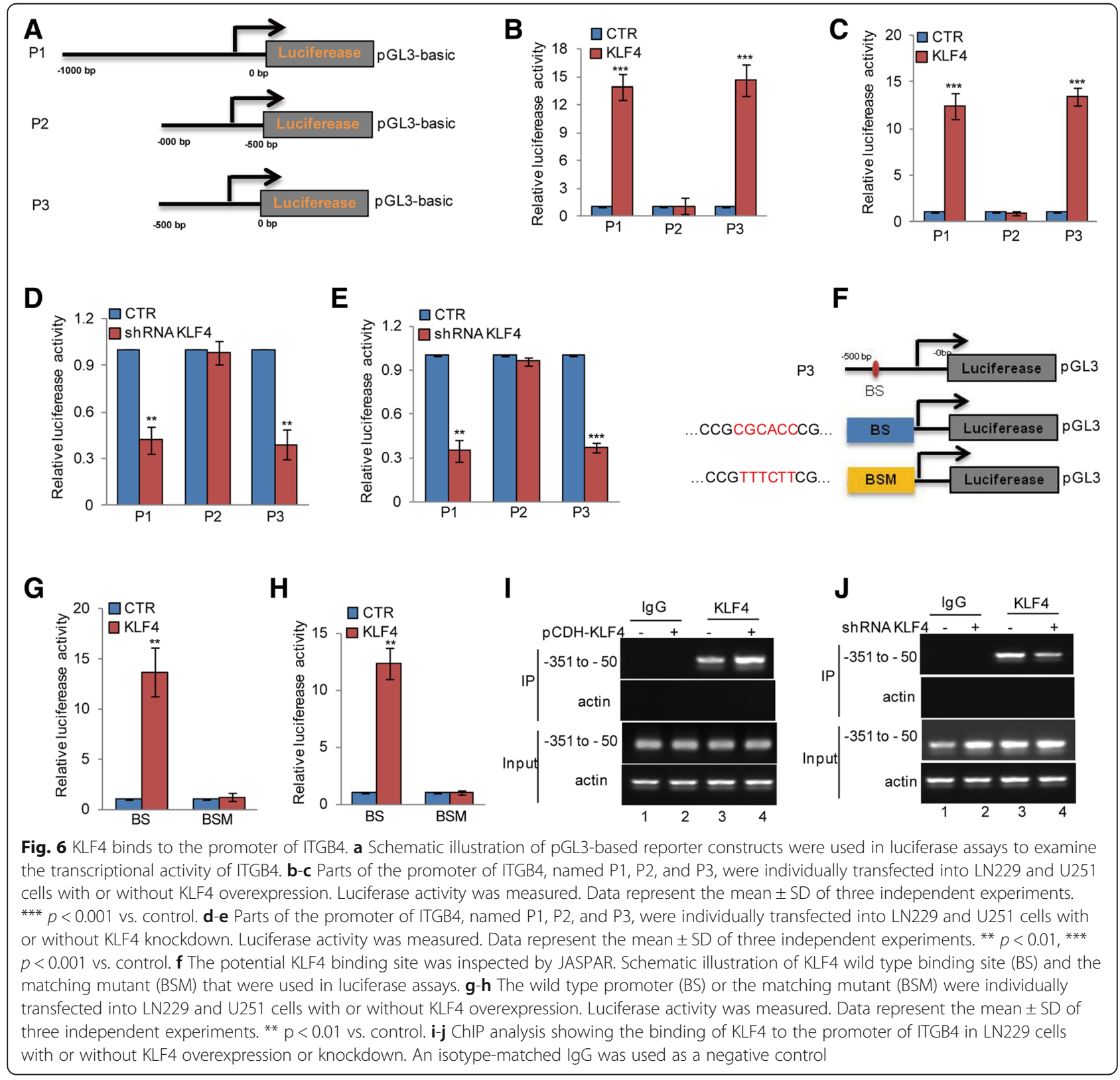




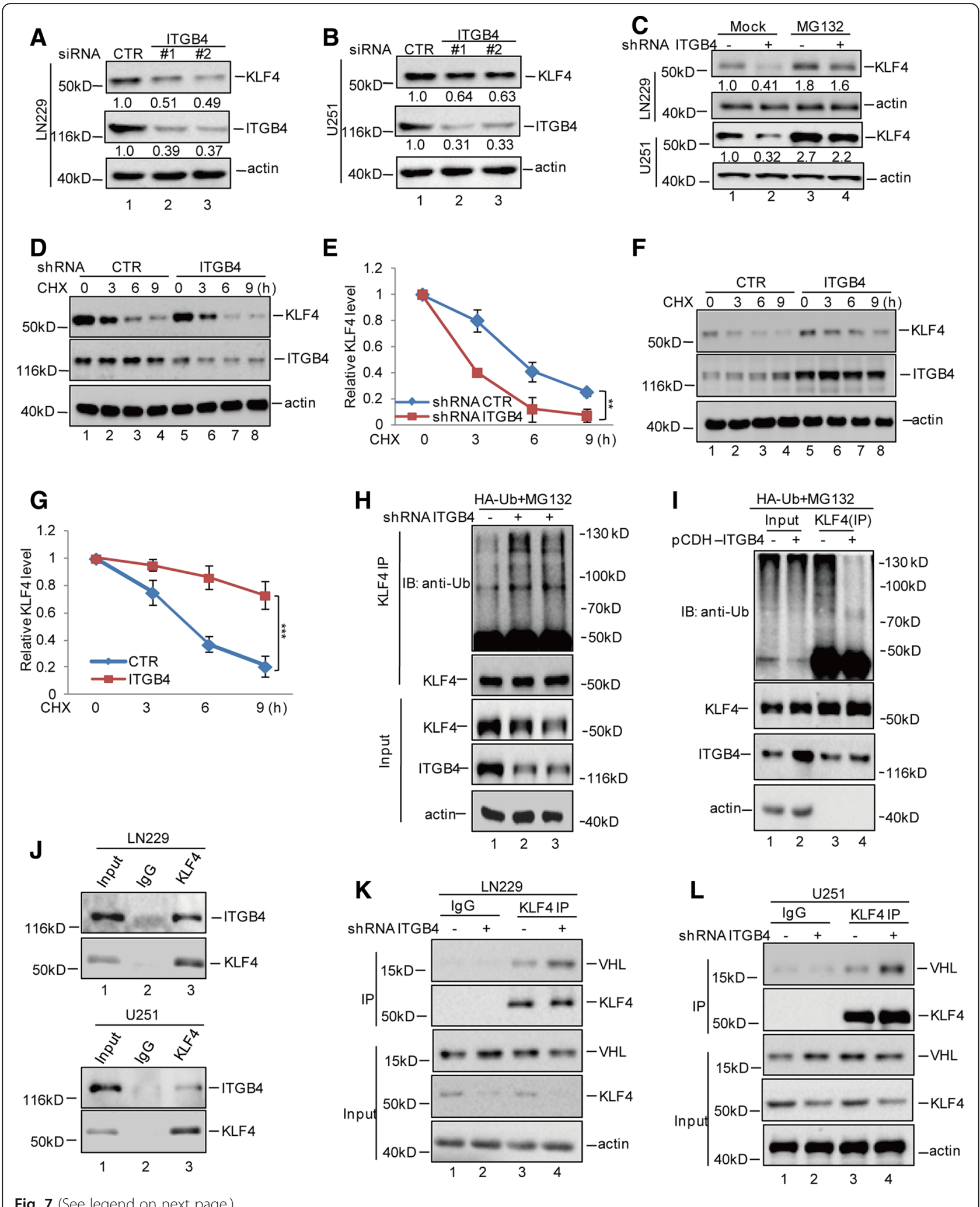

Fig. 7 (See legend on next page.) 
(See figure on previous page.)

Fig. 7 ITGB4 enhanced KLF4 stability. a-b ITGB4 was knocked down in LN229 and U251 cells. The protein levels of ITGB4 and KLF4 were analysed by western blotting assay. c LN229 and U251 cells with or without ITGB4 knockdown were treated with MG132 or not. The protein levels of ITGB4 and KLF4 were analysed by western blotting assay. $\mathbf{d}-\mathbf{g}$ LN229 cells with or without ITGB4 knockdown or overexpression were treated with $\mathrm{CHX}(10 \mathrm{mg} / \mathrm{ml})$ for the indicated times. The half-life of KLF4 was measured. Data represent the mean \pm SD of three independent experiments. ${ }^{* *} p<0.01,{ }^{* *} p<0.001$ vs. control. $\mathbf{h}$-i LN229 cells with or without ITGB4 knockdown or overexpression, were transfected with the indicated constructs and the cells then were treated with MG132 for $8 \mathrm{~h}$ before collection. The whole-cell lysate was subjected to immunoprecipitation with anti-KLF4 antibodies and western blotted with anti-Ub antibodies to detect ubiquitylated KLF4. j LN229 and U251 cell lysates were subjected to immunoprecipitation with control lgG or anti-KLF4 antibodies. The immunoprecipitates were then detected using the indicated antibodies. k-I ITGB4 was knocked down or overexpressed in LN229 cells. The cell lysates were subject to immunoprecipitation with control lgG or anti-KLF4 antibodies. The immunoprecipitates were then detected using the indicated antibodies

Figure S1A-C). To further verify this, we examined the mRNA levels of ITGB4 in seven glioma tissues and three normal brain tissues from our own institution. Similarly, increased ITGB4 mRNA expression was observed in the glioma tissues (Fig. 2e).

\section{ITGB4 is an important mediator of the stem-like properties of GSCs}

To assess the contribution of ITGB4 in promoting glioma stem-like properties, we first obtained ITGB4-positive cells from the LN229 and U251 cells by fluorescence-activated cell sorting (FACS). Compared with the ITGB4-negative cells, ITGB4 positive cells exhibited much higher Oct4 and Nanog expression (Fig. 3a-d). To further investigate the role of ITGB4 in GSCs, we enriched cancer stem cells from LN229 and U251 cells by mammosphere formation assay and then knocked down ITGB4 expression in these cells using siRNA. Compared with the control group, ITGB4 knockdown remarkably decreased the expression of the Oct 4 and Nanog stemness markers (Fig. 3e-h).

Next, we stably knocked down ITGB4 expression using lentivirus expressing short-hairpin RNA (shRNA) in LN229 and U251 cells. As shown in Additional file 2: Figure S2A-B, stable cell lines expressing these shRNAs showed significantly reduced ITGB4 levels. We then performed mammosphere formation, ALDH1-positive, and CD133-positive sorting assays to investigate the role of ITGB4 in promoting self-renewal abilities, a key characteristic of GSCs. The sphere formation efficiency was dramatically reduced upon ITGB4 depletion, as indicated by a decrease in spheroid numbers (Fig. 3i-j). Additionally, the ALDH1+ and CD133+ population was markedly decreased following the depletion of ITGB4 (Fig. 3k-n). Together, these data implied that ITGB4 is necessary for promoting cancer stem-like properties.

\section{ITGB4 knockdown suppressed glioma cell migration and proliferation in vitro and in vivo}

Given that ITGB4 suppression diminished GSC properties in vitro, we then examined whether ITGB4 knockdown could affect glioma cell migration and proliferation in vitro and in vivo. To this end, we used the LN229 and U251 cell lines and stably knocked down ITGB4 with two independent shRNAs. In the subsequent transwell assay, the migratory capabilities of LN229 and U251 cells depleted of ITGB4 were apparently decreased compared to control cells (Fig. 4a-b).

Furthermore, the numbers of colonies formed by LN229 and U251 cells with ITGB4 knockdown were also remarkably reduced compared to control cells (Fig. 4c-d). To examine the involvement of ITGB4 expression in glioma tumorigenesis in vivo, we implanted LN229 cells, stably expressing control shRNA or shRNA targeting ITGB4, into nude mice. As illustrated in Fig. 4e-g, the size and weight of xenograft tumours were significantly reduced by the ITGB4 knockdown.

\section{KLF4 upregulates ITGB4 expression in glioma cells}

KLF4/GKLF is a member of the KLF-like factor subfamily of zinc finger proteins [22]. Our recent studies have indicated that KLF4 upregulates MGLL and BIK in HCC and prostate cancer cells [23-25]. To screen the KLF4regulated genes in glioma, we overexpressed KLF4 in LN229 cells for subsequent mRNA sequencing analysis. Interestingly, among the upregulated genes, we found that ITGB4 was significantly elevated in KLF4 overexpressing cells (Fig. 5a-c).

To further confirm this, we first detected the mRNA and protein levels of ITGB4 in KLF4 overexpressing LN229 and U251 cells. Compared with the control cells, overexpression of KLF4 significantly increased ITGB4 expression (Fig. 5d-g). Conversely, inhibition of KLF4 dramatically decreased ITGB4 expression (Fig. 5h-k).

\section{KLF4 directly binds to the promoter of ITGB4}

To identify the KLF4 binding regions on the ITGB4 promoter, we first cloned the upstream sequence of ITGB4 and different truncations of it. We then inserted them into pGL3-based luciferase reporter plasmids, named P1-P3 (Fig. 6a). We transfected them into LN229 and 

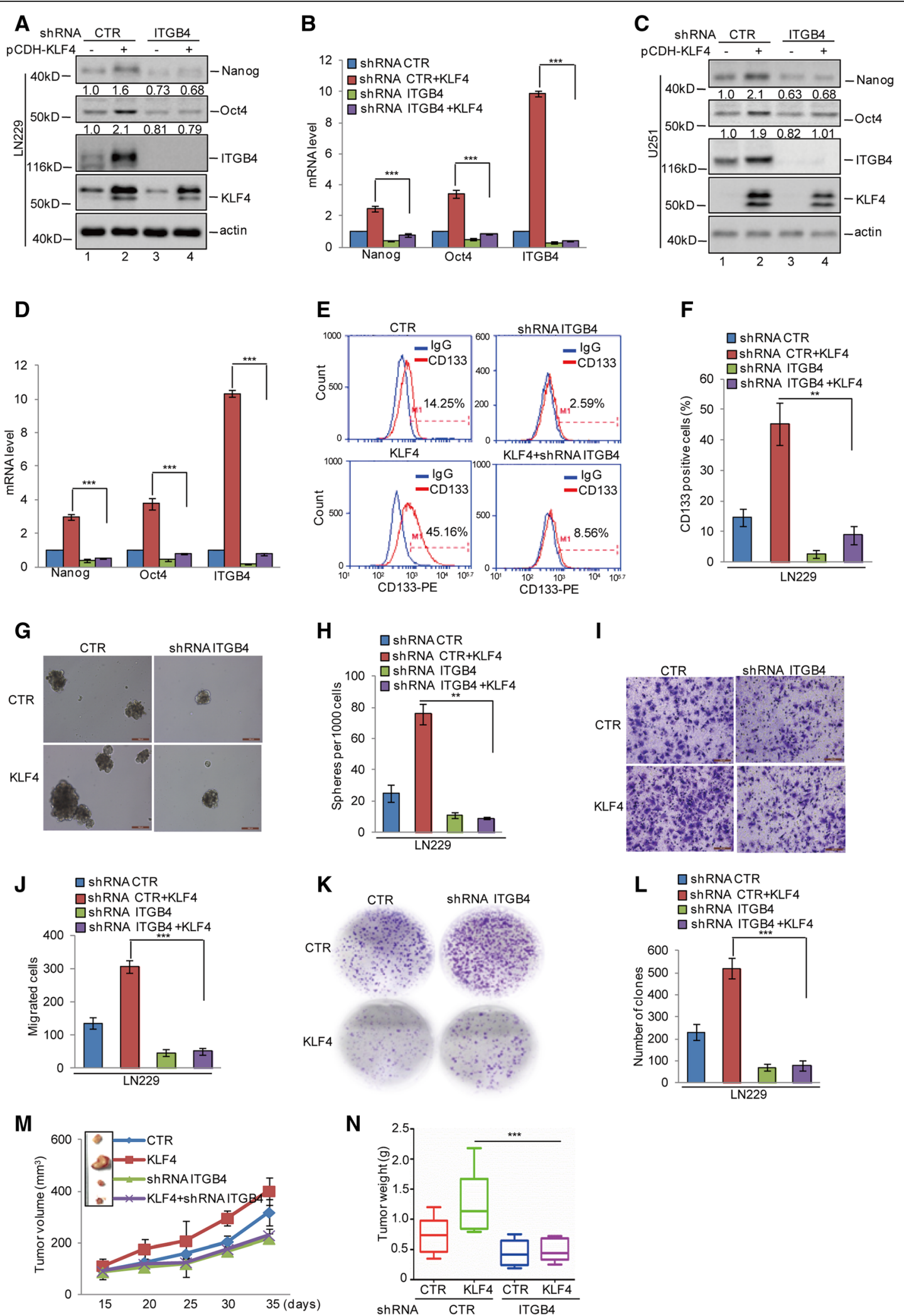

Fig. 8 (See legend on next page.) 
(See figure on previous page.)

Fig. 8 KLF4 and ITGB4 played an essential role in glioma tumorigenesis. a-d ITGB4 was knocked down in LN229 and U251 cells with or without overexpressing KLF4. The expression levels of ITGB4, Oct4, Nanog, and KLF4 were analysed by western blotting and q-RT-PCR assays. Data represent the mean \pm SD of three independent experiments. ${ }^{* *} p<0.001$ vs. control. e-h The CD133-positive populations and mammosphereforming abilities were analysed. Data represent the mean \pm SD of three independent experiments. ${ }^{* *} p<0.01$ vs. control. i-I Cell migration and proliferation were analysed by transwell and colony formation assays. Data represent the mean \pm SD of three independent experiments. *** $p<0.001$ vs. control. $\mathbf{m}-\mathbf{n}$ The cells were subcutaneously injected into nude mice ( $n=6$ in each group) for tumour formation. Representative bright-field imaging of the tumours in the mice implanted with the indicated cells. After 5 weeks, mice receiving transplants of the indicated cells were sacrificed. The tumour volume and weight were calculated. ${ }^{* *} p<0.01,{ }^{* * *} p<0.001$ vs. control

U251 cells with or without KLF4 overexpression. Compared with control cells, the luciferase activities of P1 and P3 were augmented in KLF4 overexpressing cells; however, this increase was abolished when P2 was transfected (Fig. 6b-c). To further verify this, the truncations were transfected into LN229 and U251 cells with or without KLF4 knockdown. We found that KLF4 depletion led to a decrease in luciferase activity from P1 and P3. However, this decrease disappeared when P2 was transfected in KLF4 knockdown cells (Fig. 6d-e). Taken together, these results indicate that the region from 500 to $0 \mathrm{bp}$ (P3) is a key region for the promotion of ITGB4 by KLF4.

Previous reports have indicated that KLF4 is a zinc finger-type transcription factor that usually binds to the GC rich elements of promoters [26]. To identify potential KLF4 binding sites, we inspected the sequence of the ITGB4 promoter by JASPAR software and found a putative KLF4 binding site on the ITGB4 promoter. To verify that this potential KLF4-binding site was indeed responsive to KLF4, two pGL3-based luciferase reporter plasmids named BS and BSM were established (Fig. 6f). These plasmids were individually transfected into LN229 and U251 cells with or without KLF4 knockdown. As shown in Fig. $6 \mathrm{~g}$ and $\mathrm{h}$, the luciferase activity of BS but not BSM was significantly increased in KLF4 overexpressing cells. In addition, subsequent chromatin immunoprecipitation (ChIP) assays showed that the chromatin fragments corresponding to the putative KLF4 binding sites were specifically present in the anti-KLF4 immunoprecipitates from LN229 cells. This bond was increased when KLF4 was overexpressed, whereas, the bond was decreased when KLF4 was knocked down (Fig. 6i-j).

\section{ITGB4 interacts with KLF4 and enhances its stability}

In addition to KLF4 being identified as a potential regulator of ITGB4, we also found that a positive feedback loop existed between KLF4 and ITGB4. As shown in Fig. 7a and b, we found that the knockdown of ITGB4 using siRNA led to KLF4 downregulation and that the decrease in KLF4 was restored by the proteasome inhibitor MG132. This indicated that ITGB4 affected KLF4 expression in a proteasome- dependent manner (Fig. 7c). To further validate this finding, we treated the indicated cells with the protein synthesis inhibitor cycloheximide (CHX). Notably, the depletion of ITGB4 led to a prominent decrease in the stability of endogenous KLF4 protein (Fig. 7d-e). Whereas, overexpression of ITGB4 enhanced the stability of KLF4 in LN229 cells (Fig. $7 \mathrm{f}-\mathrm{g})$. Additionally, we also found that knockdown of ITGB4 increased the ubiquitylation of KLF4 in glioma cells (Fig. 7h), while overexpression of ITGB4 decreased the ubiquitylation of KLF4 (Fig. 7i).

To uncover the molecular mechanism by which ITGB4 enhances KLF4 stability, we first wanted to investigate whether ITGB4 could interact with KLF4. The binding assays suggested that ITGB4 could interact with KLF4 in glioma cells and they were co-localization in the cells (Fig. 7 and Additional file 3: Figure S3). Subse quently, we also found that the binding of KLF4 to VHL, an E3 ligase of KLF4, was increased in ITGB4 knockdown cells (Fig. 7k). Similar to the knockdown assay, the interaction between KLF4 and VHL was decreased in ITGB4 overexpressing cells (Fig. 7l). Taken together, our data suggest that ITGB4 interacts with KLF4 and prevents its degradation.

\section{Reciprocal regulation between KLF4 and ITGB4 plays an essential role in glioma stem cell self-renewal and tumourigenesis}

Having identified that the feedback loop existed between KLF4 and ITGB4, we next asked whether reciprocal regulation between KLF4 and ITGB4 facilitated GSC self-renewal, proliferation, and migration. We first knocked down ITGB4 in LN229 and U251 cells with or without KLF4 overexpression. The expression levels of Oct4 and Nanog were analysed by western blotting and q-RT-PCR. As shown in Fig. 8a-d, KLF4 overexpression elevated the expression of Oct4 and Nanog. However, the upregulation of Oct4 and Nanog disappeared when ITGB4 was knocked down. After this, to assess the contribution of KLF4 in promoting GSC properties through regulation of ITGB4, CD133-positive sorting assays, mammosphere formation, transwell assays, and plate colony formation were performed. As shown in Fig. 8e-l, the 
elevations of the CD133+ population, sphere formation efficiency, migration ability, and colony numbers induced by KLF4 were reversed when ITGB4 was knocked down. To further confirm this, we stably overexpressed KLF4 in
LN229 cells with or without ITGB4 knockdown, then implanted these cells into nude mice. As shown in Fig. 8m and $\mathrm{n}$, we found that KLF4 overexpression promoted glioma growth as indicated by the increase in the size and

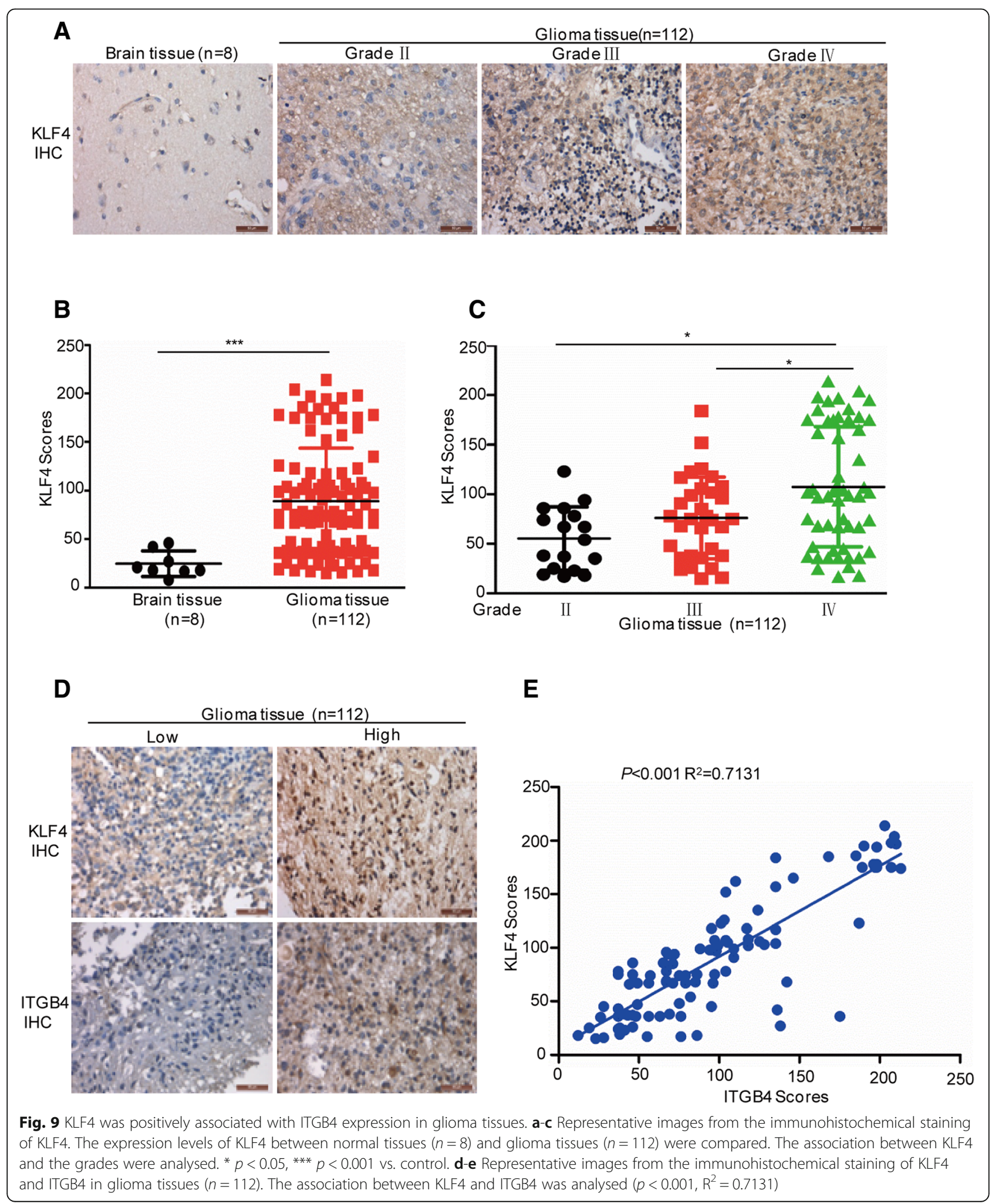


weight of xenograft tumours. However, this increase was abolished when ITGB4 was depleted.

\section{KLF4 is closely associated with glioma grades and ITGB4 expression in glioma tissues}

To evaluate the clinical relevance of the KLF4-ITGB4 axis, we first examined the expression of KLF4 in human glioma samples $(n=112$; World Health Organization (WHO) grade II-IV) and nonneoplastic brain tissue samples $(n=8)$ by immunohistochemical (IHC) staining. These results showed that KLF4 displayed higher expression levels at varying degrees, compared with nonneoplastic brain tissues. High expression of KLF4 was significantly correlated with increased tumour grade (Fig. 9a-c). In addition, we further analysed the correlation between KLF4 and ITGB4 in human glioma tissues $(\mathrm{n}=112)$. As shown in Fig. 9d and e, we found that KLF4 was closely associated with ITGB4 expression $\left(p<0.001, \mathrm{R}^{2}=0.7131\right)$.

\section{Discussion}

Most patients with glioma tend to show recurrence and poor prognosis, which are believed to be closely related to the existence of GSCs. Therefore, it is necessary to understand how GSCs maintain their stem-like properties and find GSC-related therapeutic targets to improve glioma prognosis [27-31]. In this study, our findings showed that ITGB4 expression was increased in GSCs and glioma tissues. Elevated ITGB4 levels were correlated with glioma grades. Subsequently, we found that ITGB4 knockdown decreased the self-renewal abilities of GSCs and suppressed glioma cell migration and proliferation in vitro and in vivo. Further mechanistic studies revealed that KLF4, an important transcription factor, directly binds to the promoter of ITGB4, facilitating its transcription and contributing to increased ITGB4 expression in glioma. Interestingly, when ITGB4 levels were increased, it was able to interact with KLF4 and thus decrease its binding to the E3 ligase VHL, leading to its accumulation in glioma.

There is increasing evidence to indicate that the overexpression of ITGB4 is correlated with an aggressive phenotype and poor prognosis in breast cancer, lung cancer, pancreatic cancer, cervical cancer, and gastric cancer [17]. Similarly, we found that the mRNA and protein levels of ITGB4 were increased in human glioma and GSCs. Increased ITGB4 levels played an oncogenic role in glioma and were correlated with the glioma grades. Inhibition of ITGB4 expression in glioma cells reduced the self-renewal abilities of GSCs and suppressed glioma cell migration and proliferation in vitro and in vivo.
Recently, Transmembrane protein 268 (TMEM268) was reported to increase ITGB4 expression via enhancing its stability in gastric cancer cells [32, 33]. TAp73 was indicated to transcriptionally upregulate ITGB4 expression [34]. Here, we found that KLF4 directly binds to the promoter of ITGB4, facilitating its transcription and contributed to ITGB4 increase in glioma.

KLF4 is a member of the KLF-like factor subfamily of zinc finger proteins [22]. Dysregulation of KLF4 has been observed in a number of human cancers, including gastrointestinal, pancreas, bladder, and lung cancer. Ectopic expression of KLF4 has been reported to suppress cell proliferation, induce apoptosis, and promote cell-cycle arrest, indicating that KLF4 has a tumour suppressor function in a variety of malignancies and that its downregulation may play an essential role in tumourigenesis [35-40]. For example, KLF4 was reported to suppress cell migration and invasion in esophageal cancer $[41,42]$. In gastric cancer, KLF4 inhibited cell proliferation and metastasis via downregulating $\beta$-catenin expression [43-45]. Recently, KLF4 was reported to transcriptionally repress cavelion-1 expression and thereby inhibit metastasis of pancreatic cancer [46]. However, in squamous cell carcinoma, breast cancer, osteosarcoma, and glioma, KLF4 was shown to promote cell growth and cellular dedifferentiation, and inhibit cell apoptosis [47-49]. Consistently, our data indicated that KLF4 promoted gliomagenesis via upregulating ITGB4 expression.

Interestingly, we also found that a positive feedback loop existed between ITGB4 and KLF4. ITGB4 was able to interact with KLF4 and enhanced its stability. Previous studies have indicated that the E3 ligase VHL and FOXB33 promoted KLF4 degradation in breast cancer $[50,51]$. Our data suggests that ITGB4 binds to KLF4 and suppresses its interaction with VHL.

\section{Conclusions}

Taken together, our data suggests the existence of a positive feedback loop between KLF4 and ITGB4 that promotes GSC self-renewal and gliomagenesis, and also implicates ITGB4 as a valuable therapeutic target for glioma.

\section{Additional files}

Additional file 1: Figure S1. (A) ITGB4 mRNA expression in brain tissue $(n=23)$ and diffuse astrocytoma tissues $(n=7)$ were analysed. (B) ITGB4 mRNA expression in brain tissues $(n=23)$ and anaplastic astrocytoma tissues ( $n=19$ ) were analysed. (C) ITGB4 mRNA expression in cerebellum $(n=4)$ and classic medulloblastoma $(n=23)$ were analysed. These data were extracted from the Oncomine database. (TIF $108 \mathrm{~kb}$ )

Additional file 2: Figure S2. (A-D) ITGB4 was knocked down in LN229 and U251 cells using shRNA. The expression levels of ITGB4 were analysed by western blotting and q-RT-PCR. (TIF 268 kb) 
Additional file 3: Figure S3. nuclear and cytosol proteins were isolated from LN229 cells. The expression levels of ITGB4 and KLF4 were detected by western blotting. PARP was used as nuclear marker and GAPDH was used as cytoplasm marker. (TIF $39 \mathrm{~kb}$ )

\section{Abbreviations}

GSCs: Glioma stem cells; ITGB4: Integrin $\beta 4$; KLF4: Kruppel-like Factor 4; Oct4: Octamer-binding transcription factor 4; VHL: Von Hippel-Lindau

\section{Acknowledgements}

We kindly thank the National Nature Science Foundation of China for the funding

\section{Funding}

This research was supported by the National Nature Science Foundation of China (No. 81874136 to Chuanchun Han and 81872065 to Bo Zhang); Liaoning province innovation talents support program in Colleges and Universities (LR2016023); Doctoral Scientific Research Launching Fund Project of Liaoning province (20180540069); Basic research projects in colleges and universities of Liaoning Province (LQ2017030).

\section{Authors' contributions}

$\mathrm{BZ}$ and $\mathrm{CCH}$ designed the experiments; BBM, $\mathrm{LZ}$, and YJZ conducted the molecular biology experiments and wrote the manuscript; RPH and QW conducted the pharmacological studies and performed the statistical analyses. All authors read and approved the final manuscript.

\section{Ethics approval and consent to participate}

For animal experiments, all procedures were performed in accordance with the institutional guidelines for the care and use of laboratory animals approved by the Animal Care and Use Committee of Dalian Medical University and the National Institutes of Health guide for the care and use of laboratory animals. The characteristics of the patients and their tumours were collected through the review of medical records and pathology reports. Informed consent and the approval of the ethics committee of Taizhou Hospital of Zhejiang Province were obtained. All of the methods in this study were performed in accordance with the approved guidelines, and all of the experimental protocols were approved by the ethics committee of Taizhou Hospital of Zhejiang Province.

\section{Consent for publication}

All the authors of this study give their consent for publication.

\section{Competing interests}

The authors declare that they have no competing interests.

\section{Publisher's Note}

Springer Nature remains neutral with regard to jurisdictional claims in published maps and institutional affiliations.

\section{Author details \\ ${ }^{1}$ Department of Neurosurgery, Second Affiliated Hospital, Institute of Cancer Stem Cell, Dalian Medical University, Dalian 116027, China. ${ }^{2}$ Laboratory of Pathogenic Biology, College of Basic Medical Science, Dalian Medical University, Dalian 116027, China. ${ }^{3}$ Nursing Department, First Affiliated Hospital, Dalian Medical University, Dalian 116011, China. ${ }^{4}$ Department of Neurology of Dalian Municipal Central Hospital Affiliated, Dalian Medical University, Dalian 116033, China.}

Received: 26 November 2018 Accepted: 9 January 2019 Published online: 18 January 2019

\section{References}

1. Lara-Velazquez M, Al-Kharboosh R, Jeanneret S, Vazquez-Ramos C, Mahato D, Tavanaiepour D, Rahmathulla G, Quinones-Hinojosa A. Advances in brain tumor surgery for glioblastoma in adults. Brain Sciences. 2017;7:150-166.

2. Wen PY, Kesari S. Malignant gliomas in adults. N Engl J Med. 2008;359:492-507.

3. Stupp R, Hegi ME, Mason WP, van den Bent MJ, Taphoorn MJ, Janzer RC, Ludwin SK, Allgeier A, Fisher B, Belanger K, Hau P, Brandes AA, et al. Effects of radiotherapy with concomitant and adjuvant temozolomide versus radiotherapy alone on survival in glioblastoma in a randomised phase III study: 5-year analysis of the EORTC-NCIC trial. The Lancet Oncology. 2009;10:459-66.
4. Van Meir EG, Hadjipanayis CG, Norden AD, Shu HK, Wen PY, Olson JJ. Exciting new advances in neuro-oncology: the avenue to a cure for malignant glioma. CA Cancer J Clin. 2010;60:166-93.

5. Chen J, McKay RM, Parada LF. Malignant glioma: lessons from genomics, mouse models, and stem cells. Cell. 2012;149:36-47.

6. Lathia JD, Mack SC, Mulkearns-Hubert EE, Valentim CL, Rich JN. Cancer stem cells in glioblastoma. Genes Dev. 2015;29:1203-17.

7. Reya T, Morrison SJ, Clarke MF, Weissman IL. Stem cells, cancer, and cancer stem cells. Nature. 2001;414:105-11.

8. Vescovi AL, Galli R, Reynolds BA. Brain tumour stem cells. Nat Rev Cancer. 2006;6:425-36

9. Eramo A, Ricci-Vitiani L, Zeuner A, Pallini R, Lotti F, Sette G, Pilozzi E, Larocca LM, Peschle C, De Maria R. Chemotherapy resistance of glioblastoma stem cells. Cell Death Differ. 2006;13:1238-41.

10. Flavahan WA, Wu Q, Hitomi M, Rahim N, Kim Y, Sloan AE, Weil RJ, Nakano I, Sarkaria JN, Stringer BW, Day BW, Li M, et al. Brain tumor initiating cells adapt to restricted nutrition through preferential glucose uptake. Nat Neurosci. 2013;16:1373-82.

11. Li Z, Bao S, Wu Q, Wang H, Eyler C, Sathornsumetee S, Shi Q, Cao Y, Lathia J, McLendon RE, Hjelmeland AB, Rich JN. Hypoxia-inducible factors regulate tumorigenic capacity of glioma stem cells. Cancer Cell. 2009;15:501-13.

12. Wang L, Dong Z, Zhang Y, Miao J. The roles of integrin beta4 in vascular endothelial cells. J Cell Physiol. 2012;227:474-8.

13. Lipscomb EA, Simpson KJ, Lyle SR, Ring JE, Dugan AS, Mercurio AM. The alpha6beta4 integrin maintains the survival of human breast carcinoma cells in vivo. Cancer Res. 2005;65:10970-6.

14. Stewart RL, O'Connor KL. Clinical significance of the integrin alpha6beta4 in human malignancies. Lab Invest. 2015;95:976-86.

15. Wang H, Rana S, Giese N, Buchler MW, Zoller M. Tspan8, CD44v6 and alpha6beta4 are biomarkers of migrating pancreatic cancer-initiating cells. Int J Cancer. 2013;133:416-26.

16. Gan L, Meng J, Xu M, Liu M, Qi Y, Tan C, Wang Y, Zhang P, Weng W, Sheng $W$, Huang $M$, Wang Z. Extracellular matrix protein 1 promotes cell metastasis and glucose metabolism by inducing integrin beta4/FAK/SOX2/ HIF-1alpha signaling pathway in gastric cancer. Oncogene. 2018;37:744-55.

17. Stewart RL, West D, Wang C, Weiss HL, Gal T, Durbin EB, O'Connor W, Chen M, O'Connor KL. Elevated integrin alpha6beta4 expression is associated with venous invasion and decreased overall survival in non-small cell lung cancer. Hum Pathol. 2016;54:174-83.

18. Yang ZY, Jiang H, Qu Y, Wei M, Yan M, Zhu ZG, Liu BY, Chen GQ, Wu YL, Gu QL. Metallopanstimulin-1 regulates invasion and migration of gastric cancer cells partially through integrin beta4. Carcinogenesis. 2013;34:2851-60.

19. Yang X, Du T, Wang X, Zhang Y, Hu W, Du X, Miao L, Han C. IDH1, a CHOP and C/EBPbeta-responsive gene under ER stress, sensitizes human melanoma cells to hypoxia-induced apoptosis. Cancer Lett. 2015;365:201-10.

20. Ma B, Yuan Z, Zhang L, Lv P, Yang T, Gao J, Pan N, Wu Q, Lou J, Han C, Zhang B. Long non-coding RNA AC023115.3 suppresses chemoresistance of glioblastoma by reducing autophagy. Biochim Biophys Acta. 2017;1864: 1393-404

21. Li X, Ma C, Zhang L, Li N, Zhang X, He J, He R, Shao M, Wang J, Kang L, Han C. LncRNAAC132217.4, a KLF8-regulated long non-coding RNA, facilitates oral squamous cell carcinoma metastasis by upregulating IGF2 expression. Cancer Lett. 2017:407:45-56.

22. Ghaleb AM, Yang WW. Kruppel-like factor 4 (KLF4): what we currently know. Gene. 2017:611:27-37.

23. Yang X, Zhang D, Liu S, Li X, Hu W, Han C. KLF4 suppresses the migration of hepatocellular carcinoma by transcriptionally upregulating monoglyceride lipase. Am J Cancer Res. 2018;8:1019-29.

24. Zhang D, Lin J, Chao Y, Zhang L, Jin L, Li N, He R, Ma B, Zhao W, Han C. Regulation of the adaptation to ER stress by KLF4 facilitates melanoma cell metastasis via upregulating NUCB2 expression. J Exp Clin Cancer Res. 2018; $37: 176$

25. Zhang L, Li X, Chao Y, He R, Liu J, Yuan Y, Zhao W, Han C, Song X. KLF4, a miR32-5p targeted gene, promotes cisplatin-induced apoptosis by upregulating BIK expression in prostate cancer. Cell Commun Signal. 2018;16:53.

26. Zhang W, Geiman DE, Shields JM, Dang DT, Mahatan CS, Kaestner KH, Biggs JR, Kraft AS, Yang WW. The gut-enriched Kruppel-like factor (Kruppel-like factor 4) mediates the transactivating effect of p53 on the p21WAF1/Cip1 promoter. J Biol Chem. 2000;275:18391-8.

27. Huang $Q$, Zhang $Q B$, Dong J, Wu YY, Shen $Y T$, Zhao $Y D$, Zhu $Y D$, Diao $Y$ Wang AD, Lan Q. Glioma stem cells are more aggressive in recurrent 
tumors with malignant progression than in the primary tumor, and both can be maintained long-term in vitro. BMC Cancer. 2008;8:304.

28. Codrici E, Enciu AM, Popescu ID, Mihai S, Tanase C. Glioma stem cells and their microenvironments: providers of challenging therapeutic targets. Stem Cells Int. 2016;2016:5728438.

29. Neman J, Jandial R. Decreasing glioma recurrence through adjuvant cancer stem cell inhibition. Biologics. 2010;4:157-62.

30. Jarvelin Al, Noerenberg M, Davis I, Castello A. The new (dis)order in RNA regulation. Cell Commun Signal. 2016;14:9.

31. Gomez Zubieta DM, Hamood MA, Beydoun R, Pall AE, Kondapalli KC. MicroRNA-135a regulates NHE9 to inhibit proliferation and migration of glioblastoma cells. Cell Commun Signal. 2017;15:55.

32. Hong D, Zhang X, Li R, Yu J, Lou Y, He Q, Li X, Xu D, Lv P, Lin J, Chen Y. Deletion of TMEM268 inhibits growth of gastric cancer cells by downregulating the ITGB4 signaling pathway. Cell Death Differ. 2018;10: 1476-1489.

33. Pang Y, Li C, Wang S, Ba W, Yu T, Pei G, Bi D, Liang H, Pan X, Zhu T, Gou M, Han $Y$, et al. A novel protein derived from lamprey supraneural body tissue with efficient cytocidal actions against tumor cells. Cell Commun Signal. 2017;15:42.

34. Xie N, Vikhreva P, Annicchiarico-Petruzzelli M, Amelio I, Barlev N, Knight RA, Melino G. Integrin-beta4 is a novel transcriptional target of TAp73. Cell Cycle. 2018;17:589-94.

35. He H, Li S, Hong Y, Zou H, Chen H, Ding F, Wan Y, Liu Z. Kruppel-like factor 4 promotes esophageal squamous cell carcinoma differentiation by upregulating keratin 13 expression. J Biol Chem. 2015;290:13567-77.

36. Ohnishi S, Ohnami S, Laub F, Aoki K, Suzuki K, Kanai Y, Haga K, Asaka M, Ramirez F, Yoshida T. Downregulation and growth inhibitory effect of epithelial-type Kruppel-like transcription factor KLF4, but not KLF5, in bladder cancer. Biochem Biophys Res Commun. 2003;308:251-6.

37. Wei D, Gong W, Kanai M, Schlunk C, Wang L, Yao JC, Wu TT, Huang S, Xie K. Drastic down-regulation of Kruppel-like factor 4 expression is critical in human gastric cancer development and progression. Cancer Res. 2005;65:2746-54.

38. Wei D, Kanai M, Jia Z, Le X, Xie K. Kruppel-like factor 4 induces p27Kip1 expression in and suppresses the growth and metastasis of human pancreatic cancer cells. Cancer Res. 2008;68:4631-9.

39. Kharas MG, Yusuf I, Scarfone VM, Yang VW, Segre JA, Huettner CS, Fruman DA. KLF4 suppresses transformation of pre-B cells by ABL oncogenes. Blood. 2007; 109:747-55

40. Yu T, Chen X, Zhang W, Liu J, Avdiushko R, Napier DL, Liu AX, Neltner JM, Wang C, Cohen D, Liu C. KLF4 regulates adult lung tumor-initiating cells and represses K-Ras-mediated lung cancer. Cell Death Differ. 2016;23:207-15.

41. Yang Y, Katz JP. KLF4 is downregulated but not mutated during human esophageal squamous cell carcinogenesis and has tumor stage-specific functions. Cancer Biol Ther. 2016;17:422-9.

42. Melzer $C$, Hass $R$, von der Ohe J, Lehnert $H$, Ungefroren $H$. The role of TGFbeta and its crosstalk with RAC1/RAC1b signaling in breast and pancreas carcinoma. Cell Commun Signal. 2017;15:19.

43. Corbi-Verge C, Kim PM. Motif mediated protein-protein interactions as drug targets. Cell Commun Signal. 2016;14:8.

44. Zhang N, Zhang J, Shuai L, Zha L, He M, Huang Z, Wang Z. Kruppel-like factor 4 negatively regulates beta-catenin expression and inhibits the proliferation, invasion and metastasis of gastric cancer. Int J Oncol. 2012;40:2038-48.

45. Ortiz-Montero P, Londono-Vallejo A, Vernot JP. Senescence-associated IL-6 and IL-8 cytokines induce a self- and cross-reinforced senescence/ inflammatory milieu strengthening tumorigenic capabilities in the MCF-7 breast cancer cell line. Cell Commun Signal. 2017:15:17.

46. Zhu Z, Yu Z, Wang J, Zhou L, Zhang J, Yao B, Dou J, Qiu Z, Huang C. Kruppel-like factor 4 inhibits pancreatic Cancer epithelial-to-mesenchymal transition and metastasis by Down-regulating Caveolin-1 expression. Cell Physiol Biochem. 2018;46:238-52.

47. Tang G, Liu D, Xiao G, Liu Q, Yuan J. Transcriptional repression of FOXO1 by KLF4 contributes to glioma progression. Oncotarget. 2016;7:81757-67.

48. Nagata T, Shimada Y, Sekine S, Moriyama M, Hashimoto I, Matsui K, Okumura T, Hori T, Imura J, Tsukada K. KLF4 and NANOG are prognostic biomarkers for triple-negative breast cancer. Breast Cancer. 2017;24:326-35.

49. Zhang L, Zhang L, Xia X, He S, He H, Zhao W. Kruppel-like factor 4 promotes human osteosarcoma growth and metastasis via regulating CRYAB expression. Oncotarget. 2016;7:30990-1000.
50. Gamper AM, Qiao X, Kim J, Zhang L, DeSimone MC, Rathmell WK, Wan Y. Regulation of KLF4 turnover reveals an unexpected tissue-specific role of pVHL in tumorigenesis. Mol Cell. 2012;45:233-43.

51. Zhou H, Liu Y, Zhu R, Ding F, Wan Y, Li Y, Liu Z. FBXO32 suppresses breast cancer tumorigenesis through targeting KLF4 to proteasomal degradation. Oncogene. 2017;36:3312-21.

\section{Ready to submit your research? Choose BMC and benefit from:}

- fast, convenient online submission

- thorough peer review by experienced researchers in your field

- rapid publication on acceptance

- support for research data, including large and complex data types

- gold Open Access which fosters wider collaboration and increased citations

- maximum visibility for your research: over $100 \mathrm{M}$ website views per year

At BMC, research is always in progress.

Learn more biomedcentral.com/submissions 